\title{
Infection Control and Preventive Guidelines against COVID-19 in Dentistry
}

\author{
Priyanka Ramteke ${ }^{1}$, Rohan Sawant ${ }^{2}$, Nilker Vimala ${ }^{3}$, Rahul Ramteke ${ }^{4}$
}

\begin{abstract}
Globally, a new public health disease has emerged threatening the world. Due to the spread of 2019 novel coronavirus which is named as 2019-nCoV and causes severe acute respiratory syndrome coronavirus 2 (SARS-CoV-2). Virus is found to be zoonotic, originating in bats and further transmitted to humans through yet unknown intermediary transmitters or channels in Wuhan, Hubei province of China and discovered in December 2019. This novel coronavirus (COVID-19) is highly infectious and now human-to-human transmission is rampant. The coronavirus was recently found in saliva of infected patients after taking their swabs. In this point-of-view article, we discuss the potential of transmission of this virus via the droplets of saliva emitted when the infected person opens his or her mouth. This study has been especially focused on such scenarios arising in the dental practice setup. There seems to be high risk of transmission of novel coronavirus via contact with droplets and aerosols generated during dental clinical procedures. Here, we will be exploring such transmission scenarios and recommend the infection control measures during dental practice to block the person-to-person transmission routes in dental clinics and hospitals.
\end{abstract}

Keywords: Coronavirus, Dental practice management, Dental public health, Dental transmission, Infection control.

Journal of Operative Dentistry and Endodontics (2020): 10.5005/jp-journals-10047-0092

\section{INTRODUCTION}

The 2019 novel coronavirus (2019-nCoV) or the severe acute respiratory syndrome coronavirus 2 (SARS-CoV-2) as it is now called, is rapidly spreading from its origin in Wuhan City of Hubei Province of China to the rest of the world. ${ }^{1}$ Till 14th of April, more than 2,000,000 cases and 125,000 deaths have been reported due to COVID-19. ${ }^{2}$ In India, the virus has spread to every state and district and causing at least 1,000 daily deaths in early days of September 2020. Coronaviridae is a family of enveloped, positive-sense, singlestranded RNA that contain largest known RNA genomes with a length of up to $32 \mathrm{~kb}$. They are a family of viruses are known to be zoonotic or transmitted from animals to humans and now humanto-human transmission. Coronaviruses have caused two largescale pandemics in the past two decades, severe acute respiratory syndrome (SARS 2002) and Middle East respiratory syndrome (MERS). ${ }^{4}$ It is found that the novel coronavirus has similarity to coronavirus species found in bats and potentially in pangolins, thus confirming the zoonotic nature of this new virus.,

This disease outbreak-which started from a local seafood market in China - has grown substantially causing to infect 2,761 people in China, is associated with 80 deaths and 10 additional countries by January $2020 .^{7}$ This has raised an alarm to WHO and as per the WHO situation report (April 20, 2020) update on COVID-19 disease report, there have been more than two million reported cases and more than hundred and fifty thousand deaths worldwide (Fig. 1). ${ }^{8}$ Due to highly infectious nature of this disease, daily new cases in India have crossed 80,000 by September 2020.

Therefore, measures for prevention, identification, and management must be in place and followed during dental procedures and patient interactions for reducing the further spread of the virus as well as providing requisite dental care to patients. Given the widespread reports of novel coronavirus's spread to healthcare providers, ${ }^{4,9}$ it is reported that dental care professionals are at severe high risk for nosocomial infection. If appropriate precautions are not taken during their practice, then

\footnotetext{
1,3 Department of Conservative Dentistry and Endodontics, Dr DY Patil University School of Dentistry, Navi Mumbai, Maharashtra, India

${ }^{2}$ Dr DY Patil, School of Medicine, Apollo Hospital, Navi Mumbai, Maharashtra, India

${ }^{4}$ Department of Computer Science and Engineering, NIT Rourkela, Odisha, India
}

Corresponding Author: Priyanka Ramteke, Department of Conservative Dentistry and Endodontics, Dr DY Patil University School of Dentistry, Navi Mumbai, Maharashtra, India, Phone: +91 8928187627, e-mail: priyanka.sawant1989@yahoo.com

How to cite this article: Ramteke P, Sawant R, Vimala N, et al. Infection Control and Preventive Guidelines against COVID-19 in Dentistry. J Oper Dent Endod 2020;5(1):25-38.

Source of support: Nil

Conflict of interest: None

they can become potential carriers of the disease. Such risks in dental practice can be attributed to the patient interactions unique to dental practice only, which include aerosol generation, handling of sharps for examination, and proximity of the care provider to the patient's oropharyngeal region. Thus, there is high risk of coming in contact with droplets of saliva and aerosol generated, which has very high potential to spread the disease at a long range.

This article provides a bird's eye view regarding this new virus and measures to be taken to prevent its spread during dental practice. Since data regarding this virus are rapidly evolving, readers are urged to update themselves frequently by referring WHO website.

\section{Route of Transmission}

The common transmission routes of novel coronavirus include transmission by coming in direct contact of the career (cough, sneeze, and droplet inhalation transmission) and surface contact 


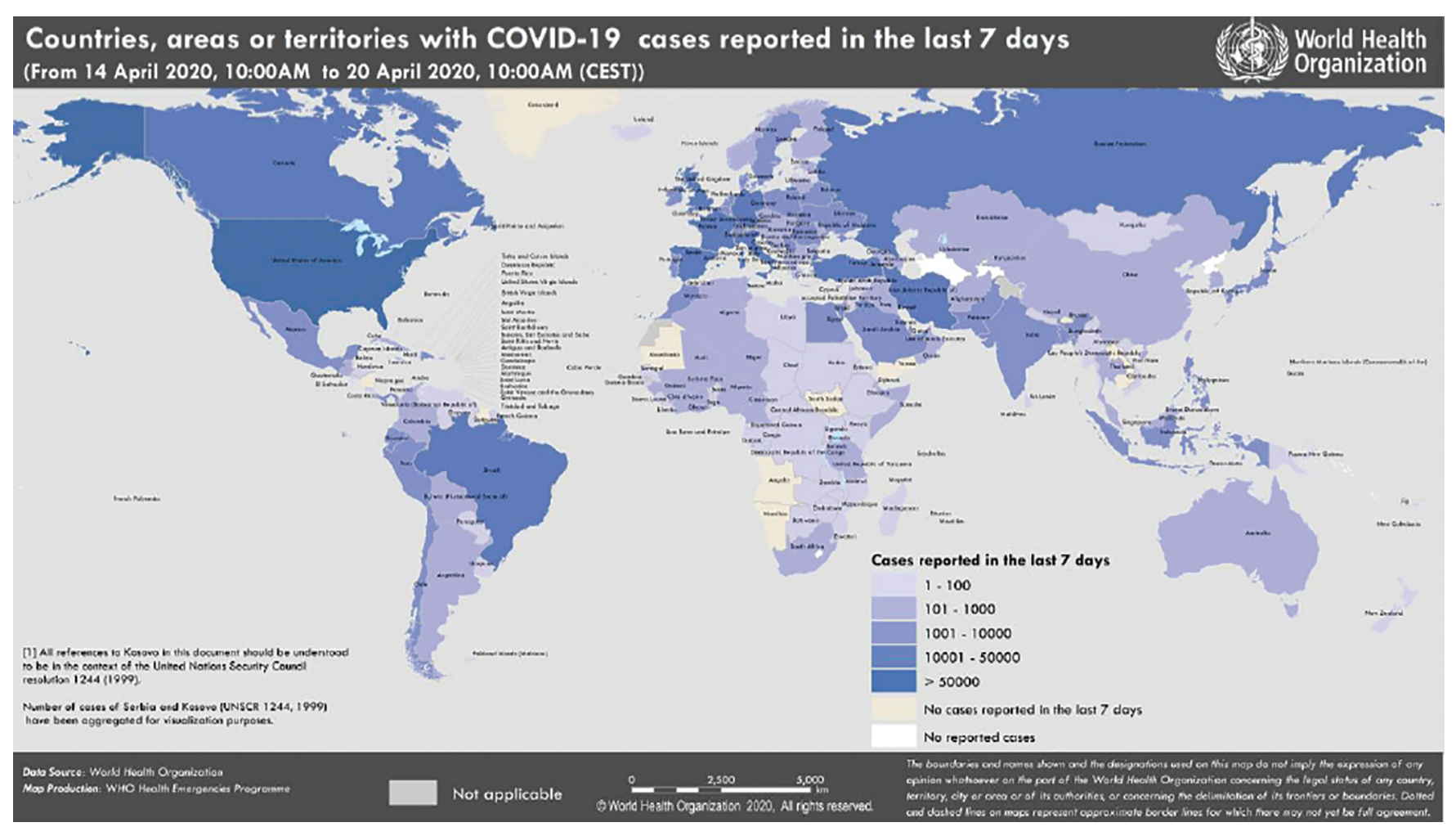

Fig. 1: Countries with reported confirmed cases of COVID-19, 20 April 2020

transmission (contact with oral, nasal, and eye mucous membranes) of had or body parts or any surface containing the virus. ${ }^{10}$ Although common clinical manifestations of novel coronavirus infection do not include eye symptoms, it is also found to be causing red eye symptoms in patients and the effect is not only limited to respiratory tracts of the infected person, ${ }^{11}$ while it is true that eye exposure may provide an effective way for the virus to enter the body. ${ }^{12}$ In addition, studies have shown that 2019-nCoV transmission through saliva or respiratory droplets is most common which and there is a high probability for dental practitioner to face such circumstances. ${ }^{13}$ The virus was also found to be present in the stool and contamination of the virus in water supply and subsequently transmission via aerosolization during dental procedure/fecal-oral route is also hypothesized. ${ }^{14}$ As per current information, transplacental transmission from pregnant women to their fetus or on to newborn baby has not been confirmed..$^{15}$ Since $2019-n C o V$ can be passed directly from person to person by respiratory droplets during contact with infected person, there is emerging evidence that the novel coronavirus can also get transmitted through fomites. ${ }^{11,16}$

\section{Transmission Routes of 2019-NCoV in Dental Clinics}

The pathogenic microorganisms can be transmitted in dental clinics through inhalation of airborne microorganisms generated during treatment of dental patients. These microorganisms can remain suspended in the air for a long time period. ${ }^{17}$ Transmission can also occur through direct contact with blood, oral fluids, ${ }^{18}$ contact of conjunctival, nasal, or oral mucosa with droplets and aerosols containing microorganisms generated from an infected individual and propelled a short distance by coughing and talking without a mask. ${ }^{19,20}$ The indirect contact which is a surface-to-surface contact with contaminated instruments and/or environmental surfaces, ${ }^{21}$ and then subsequently entry through eye, nasal, or mouth infection route. Therefore, there is a high potential for transmission of coronavirus via aerosol, fomites, or the fecal-oral route that may contribute to nosocomial spread in the dental office setting. ${ }^{22}$ Infections could be transmitted through any of these conditions involved in an infected individual in dental clinics and hospitals, especially during the outbreak of 2019-nCoV.

\section{Clinical Features}

A suspect case is defined as one with fever, sore throat, and cough who has history of travel to China or other areas of persistent local transmission or contact with patients with similar travel history or those with confirmed COVID-19 infection. However, cases with positive results of test may be asymptomatic or even without fever or cough. A confirmed case is a suspect case with a positive molecular test. ${ }^{23}$ The clinical features of COVID-19 are varied, ranging from asymptomatic state to acute respiratory distress syndrome and multiorgan dysfunction. The common clinical features include fever (not in all), cough, sore throat, headache, fatigue, headache, myalgia, and breathlessness. Conjunctivitis has also been described. ${ }^{2}$ The chest X-ray (CXR) usually shows bilateral infiltrates but may be normal in early disease. The CT is more sensitive and specific. CT imaging generally shows infiltrates, ground-glass opacities, and subsegmental consolidation. It is also abnormal in asymptomatic patients/patients with no clinical evidence of lower respiratory tract involvement. In fact, abnormal CT scans have been used to diagnose COVID-19 in suspect cases with negative molecular diagnosis; many of these patients had positive molecular tests on repeat testing. ${ }^{24}$ 


\section{Incubation Period}

The incubation period of COVID-19 has been estimated at 5-6 days on average, but there is evidence that it could be as long as 14 days, which is now the commonly adopted duration for medical observation and quarantine of (potentially) exposed persons. ${ }^{25}$

\section{Risk Factors to Dentist}

Studies have shown the presence of SARS-CoV-2 in saliva of the affected patients. ${ }^{12,26}$ To et al. reported that live viruses were present in the saliva of infected individuals by viral culture method. ${ }^{12}$ It is known that SARS-CoV-2 can bind to human angiotensin-converting enzyme 2 receptors, which are highly concentrated in salivary glands; this may be a possible explanation for the presence of SARSCoV-2 in secretory saliva. ${ }^{27,28}$ Dental patients who cough, sneeze, or receive dental treatment including the use of a high-speed handpiece or ultrasonic instruments make their secretions, saliva, or blood aerosolize to the surroundings. Dental apparatus could be contaminated with various pathogenic microorganisms after use or become exposed to a contaminated clinic environment. Therefore, infections can occur through the puncture of sharp instruments or direct contact between mucous membranes and contaminated hands. The airborne spread of severe acute respiratory syndrome coronavirus (SARS-CoV) is well-reported in many literatures. The dental papers show that many dental procedures produce aerosols and droplets that are contaminated with virus. ${ }^{29}$ Thus, droplet and aerosol transmission of 2019-nCoV are the most important concerns in dental clinics and hospitals, because it is hard to avoid the generation of large amounts of aerosol. ${ }^{19}$ In addition to the infected patient's cough and breathing, dental devices, such as high-speed dental handpiece, use high-speed gas to drive the turbine to rotate at high speed and work with running water. Particles of droplets and aerosols are small enough to stay airborne for an extended period before they settle on environmental surfaces or enter the respiratory tract. Thus, the $2019-n C o V$ has the potential to spread through droplets and aerosols from infected individuals in dental clinics and hospitals.

\section{Steps to Establish COVID-19-free Dental Practice}

Due to the unique characteristics of dental procedures where a large number of droplets and aerosols could be generated, the standard protective measures in daily clinical work are not effective enough to prevent the spread of COVID-19, especially when patients are in the incubation period, are unaware they are infected, or choose to conceal their infection. ${ }^{30}$

The healthcare workers are at the greatest risk of COVID-19 transmission. In the SARS outbreak of $2002,21 \%$ of those affected were healthcare workers. ${ }^{31}$ Till date of this article was written, almost 1,500 healthcare workers in China have been infected with 6 deaths. The doctor who first warned about the virus has died too. On March 15, 2020, the New York Times published an article entitled "The Workers Who Face the Greatest Coronavirus Risk", where an impressive schematic figure (Fig. 2) described that dentists are the workers most exposed to the risk of being affected by COVID-19. It is crucial that dental surgeon should be familiar with how 2019nCoV is spread, how to identify patients with 2019-nCoV infection, and what extra-protective measures should be adopted during the practice, in order to prevent the transmission of $2019-n C o V .{ }^{32}$ On 1st April, the ADA also published an Interim Guidance for Management of Emergency and Urgent Dental Care. Below in Table 1, we list the

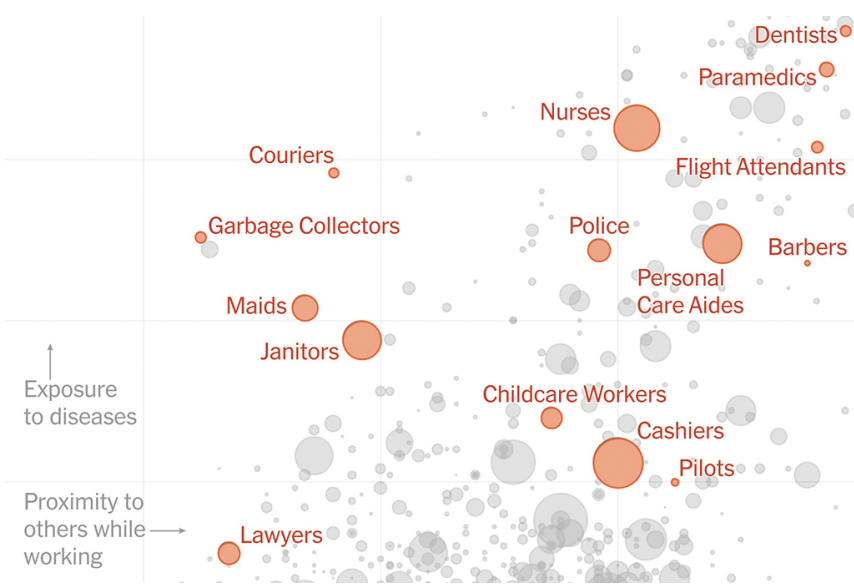

Fig. 2: March 15, 2020, the New York Times entitled impressive schematic report: "The Workers Who Face the Greatest Coronavirus Risk"

recommended measures for the infection control that should be followed by dental professionals, particularly considering the fact that aerosols and droplets were considered as the main spread routes of 2019-nCoV. ${ }^{33,34}$

\section{Precautionary Measures to be Adopted before Dental Care Starts}

Dentist and Dental Team Preparation

Safety of the staff:

- Ensure that the dental healthcare personnel (DHCP) have received their seasonal flu vaccine.

- Dental healthcare personnel experiencing influenza-like-illness (ILI) (fever with either cough or sore throat, muscle aches, temperature) should not report to work.

- Dental healthcare personnel who are of older age, have a preexisting, medically compromised condition, pregnant, etc., are perceived to be at a higher risk of contracting COVID-19 from contact with known or suspected COVID-19 patients.

- All DHCPs should self-monitor their condition by remaining alert to any respiratory symptoms (e.g., cough, shortness of breath, sore throat) and check their temperature twice a day, regardless of the presence of other symptoms consistent with a COVID19 infection. Dental offices should create a plan for whom to contact if an employee develops fever or respiratory symptoms to determine whether medical evaluation is necessary.

- To prevent transmission to DHCP or other patients, contact your local health department immediately if you suspect a patient has COVID-19. You can also contact your state health department. It is important to report such condition in Mobile Apps of the government. For instance in India, Arogya Setu Mobile App should be used to update details.

- "Designate convalescent (DHCP) provision of care to known or suspected COVID-19 patients (those who have clinically recovered from COVID-19 and may have some protective immunity) to preferentially provide care". This means that providers who have recently contracted and recovered from a COVID-19 infection should be the preferred personnel providing care.

- "Maintain an inventory of available personal protective equipment (PPE) supplies (e.g., surgical masks, surgical gowns, surgical gloves, face shields) and ensure it's use at appropriate time". 
Table 1: Interim guidance for management of emergency and urgent dental care

\begin{tabular}{|c|c|c|}
\hline \multirow[t]{7}{*}{ Before dental care starts } & (1) Dentist and dental team preparation. & (a) Ensuring safety of staff. \\
\hline & & (b) Office set-up. \\
\hline & & (c) Appointment scheduling. \\
\hline & $\begin{array}{l}\text { (2) Screening for COVID-19 status and triaging for } \\
\text { dental treatment. }\end{array}$ & $\begin{array}{l}\text { (a) Phone screening for COVID- } 19 \text {. } \\
\text { (b) Who can be seen in the dental } \\
\text { setting? }\end{array}$ \\
\hline & & (c) Referrals. \\
\hline & (3) Instructions for patient arrival. & (a) Social distancing and waiting area. \\
\hline & & (b) Infection control etiquette. \\
\hline \multirow[t]{3}{*}{ During dental care } & $\begin{array}{l}\text { (4) Standard and transmission precautions and } \\
\text { personal protective equipment (PPE) }\end{array}$ & $\begin{array}{l}\text { (a) Standard precautions. } \\
\text { (b) Transmission-based precautions. } \\
\text { (c) Use of masks and respirators. } \\
\text { (d) Donning and doffing. }\end{array}$ \\
\hline & $\begin{array}{l}\text { (5) Clinical technique (handpieces, equipment, } \\
\text { etc.). }\end{array}$ & $\begin{array}{l}\text { Technical approaches and equipment to help } \\
\text { reduce transmission. }\end{array}$ \\
\hline & (6) Steps after suspected, unintentional exposure. & \\
\hline \multirow[t]{3}{*}{ After dental care is provided } & (7) In-between patients & $\begin{array}{l}\text { Cleaning and sanitizing surfaces and } \\
\text { equipment. }\end{array}$ \\
\hline & (8) Postoperative instructions for patients. & Medications as adjuncts to care. \\
\hline & (9) When going home after a workday. & $\begin{array}{l}\text { Steps to prevent disease transmission between } \\
\text { work and home. }\end{array}$ \\
\hline
\end{tabular}

\section{Office setup:}

- Remove magazines, reading materials, toys, and other objects that may be touched by others and which are not easily disinfected.

- Print and place signage in the dental office for instructing patients on standard recommendations for respiratory hygiene/ cough etiquette and social distancing.

\section{Appointment scheduling:}

- Schedule appointments apart enough to minimize possible contact with other patients in the waiting room.

- Prevent patients from bringing companions to their appointment, except for instances where the patient requires assistance (e.g., pediatric patients, people with special needs, elderly patients, etc.).

- If companions are allowed for patients receiving treatment, they should also be screened too for signs and symptoms of COVID19 during patient check-in and should not be allowed entry into the facility if signs and symptoms are present (e.g., fever, cough, shortness of breath, sore throat). Companions should not be allowed in the dental office if perceived to be at a high risk of contracting COVID-19 (e.g., having a preexisting medically compromised condition). Any person accompanying a patient should be prohibited in the dental operatory.

\section{Screening for COVID-19 Status and Triaging for Dental Treatment}

Phone screening for COVID-19:

- A recommendation from WHO as of 16 th March was for "Dentists nationwide to postpone elective procedures for the next three weeks. Concentrating on emergency dental care will allow us to care for our emergency patients and alleviate the burden that dental emergencies would place on hospital emergency departments". State and local mandates as well as regional variation in infection rates may affect the guidance on postponement period going forward (Algorithm 1) (Fig. 3A).

- Make every effort to interview the patient by telephone, text monitoring system, or video conference before the visit.

\section{Who can be Seen in the Dental Setting?}

- If an emergency or urgent dental patient does not have a fever and is otherwise without even mild symptoms consistent with COVID-19 infection (e.g., fever, sore throat, cough, difficulty breathing), they can be seen in dental settings with appropriate protocols and personal protective equipment (PPE) in place (Algorithms 2 and 3) (Figs 3B and 3C).

- If an emergency or urgent dental patient has a fever strongly associated with a dental diagnosis (e.g., pulpal and periapical dental pain and intraoral swelling is present), but no other signs/ symptoms of COVID-19 infection (e.g., fever, sore throat, cough, difficulty breathing), they can be seen in dental settings with appropriate protocols and PPE in place (Algorithms 2 and 3).

- If an emergency or urgent dental patient does exhibit signs and symptoms of respiratory illness, the patient should be referred for emergency care where appropriate transmission-based precautions are available (Algorithm 2).

- Patients with a resolved COVID-19 infection can be seen in a dental setting:

- At least 3 days (72 hours) since COVID-19 infection symptoms resolved AND

- At least 7 days since their symptoms first appeared (defined as resolution of fever without the use of fever-reducing medications and improvement in respiratory symptoms) (e.g., cough, shortness of breath). 

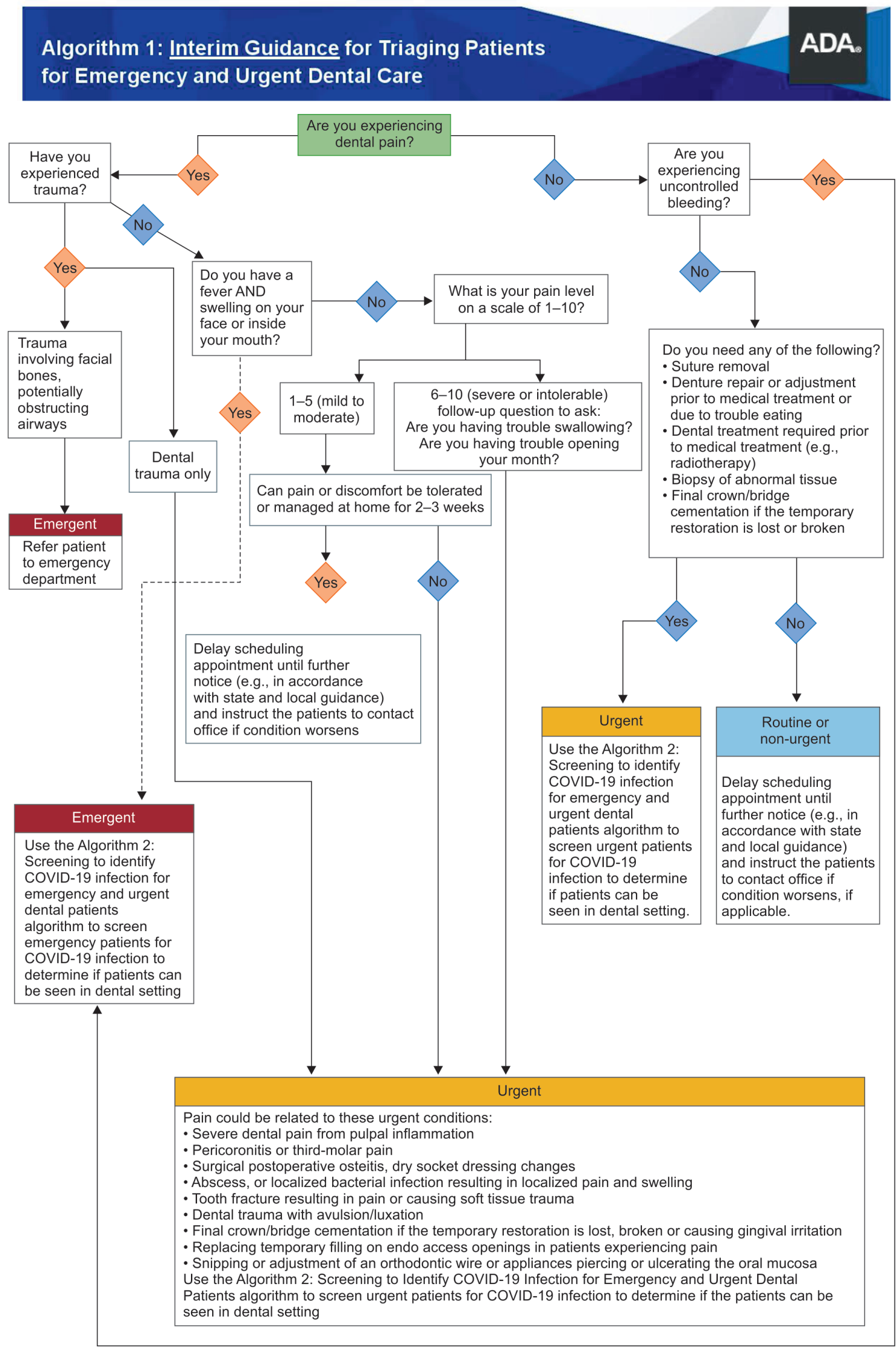

Fig. 3A: Interim guidance for triaging patients for emergency and urgent dental care 


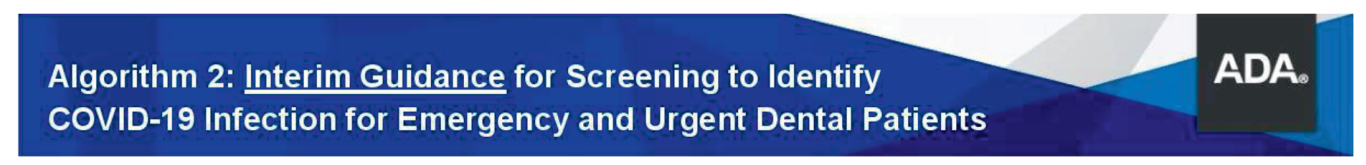

Summary of Procedures

1. Clinic staff should speak to all the patients 1-2 working days (or sooner if able) before any scheduled session.

2. Call patients for whom in-person visit may not be necessary and issue can be solved without an office visit.

Emergency and urgent dental patients in this algorithm are being evaluated for COVID-19 infection

signs/symptoms to determine in which clinical setting they should be seen. Patients with active

COVID-19 infection should not be seen in dental settings per CDC guidance.

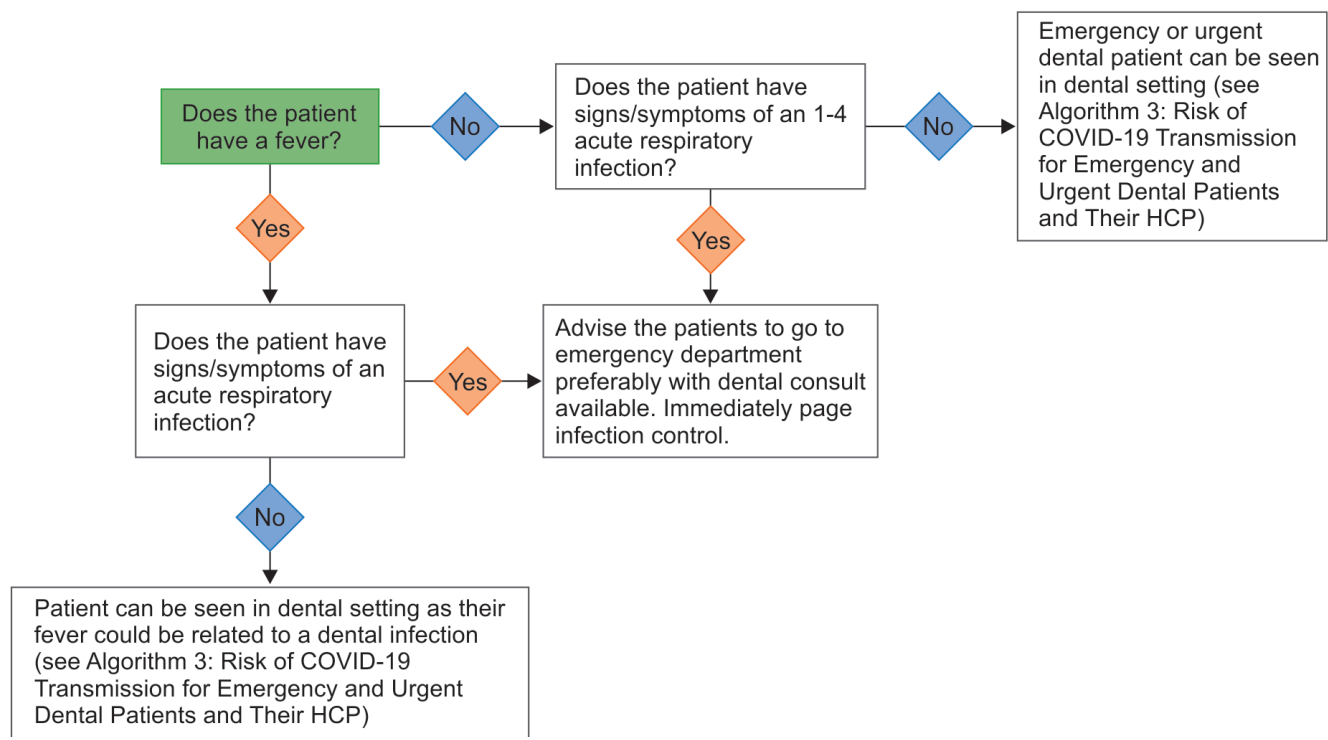

Fig. 3B: Interim guidance for screening to identify COVID-19 infection for emergency and urgent dental patients

Referrals: If the patient needs to be referred for COVID-19 testing, they should be provided detailed instructions on when/where to go for testing, how to justify the need for testing to the testing facility visited, and how to contact the dental clinic to report test results. Clinic director and/or coordinators should maintain a list of patients who will not be coming in for in-person visits in charts or find another mechanism that fits into the clinic's workflow. It is critical that a list of dental patients that have been referred to other settings due to suspected COVID-19 infection be maintained (Figs 4A and 4B).

\section{Instructions for Patient Arrival}

Social distancing and waiting area: Patient placement: Facilities should have space in waiting areas for ill patients to sit separated from other patients by at least 6 feet. Medically stable patients might opt to wait in a personal vehicle or outside the healthcare facility where they can be contacted by mobile phone when it is their turn to be seen.

Infection control etiquette: Put on a cloth face covering or face mask before entering the building and await screening for fever and symptoms of COVID-19. Face mask should be worn properly covering nose and mouth. Hand sanitizer dispensing machine should be installed with appropriate instructions on its usage.

Perform frequent hand hygiene, and restrict their visit to the patient's room or other area designated by the facility.

\section{During Dental Care}

\section{Standard and Transmission Precautions and PPE}

Standard precautions: Dental healthcare personnel should adhere to standard precautions, which "are the minimum infection prevention practices include: Hand hygiene, use of PPE, respiratory hygiene/etiquette, sharps safety, safe injection practices, sterile instruments and devices, clean and disinfected environmental surfaces".

Transmission-based precautions: If available, DHCP should implement transmission-based precautions. "Necessary transmission-based precautions might include patient placement (e.g., isolation) maintaining physical distance, adequate room ventilation, respiratory protection (e.g., $\mathrm{N}-95$ masks) for $\mathrm{DHCP}$, or postponement of nonemergency dental procedures".

Use of masks and respirators: Wear a surgical mask and eye protection with solid side shields or a face shield to protect mucous membranes of the eyes, nose, and mouth during procedures likely to generate splashing or spattering (large droplets) of blood or other body fluids.

Surgical masks are one time use only, and one mask should be used per patient.

If your mask is damaged or soiled, or if breathing through the mask becomes difficult, you should remove the face mask, discard it safely, and replace it with a new one. 

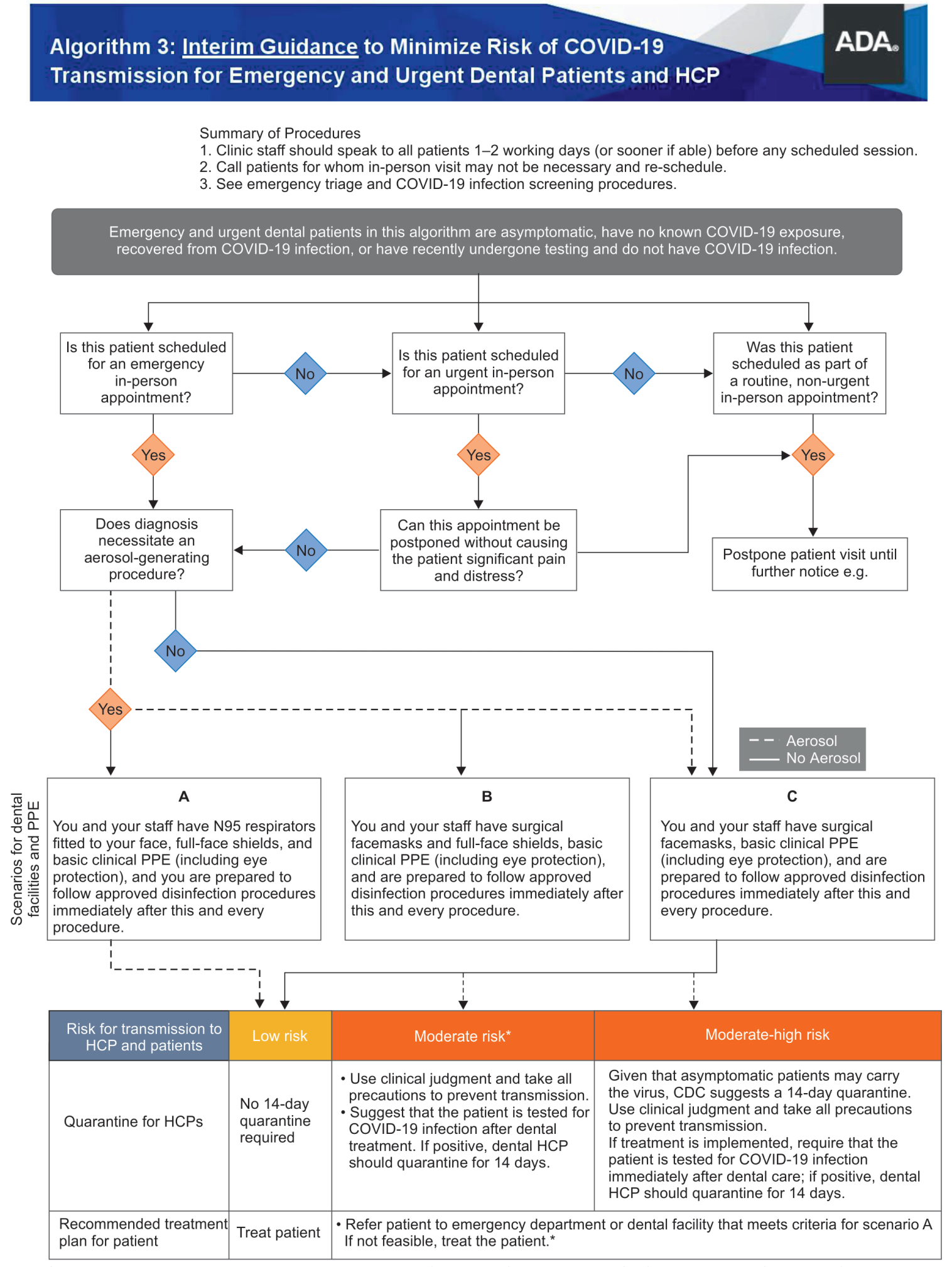

*A less protective option than N95 respirators is the use of a surgical face mask with a full-face shield; use of a surgical face mask alone may be considered if the supply chain of respirators cannot meet demand with the understanding that this may increase the risk of infection of dental healthcare professionals engaged in the care and community transmission

These algorithms are interim guidance informed by the latest recommendations from healthcare agencies (e.g., World Health Organization, Centers for Disease Control and Prevention) and the scientific literature. They will be revised and updated as new data emerge.

HCP: healthcare personnel; PPE: personal protective equipment

Fig. 3C: Interim guidance to minimize risk of COVID-19 transmission for emergency and urgent dental patients and HCP 
CDC2019-nCovid: $\square$

- . PATENT IDENTIFIER INFORMATION IS NOT TRANSMTTED TO COC.

Patient first name Datient last name
Human Infection with 2019 Novel Coronavirus
Case Report Form

Clinical course, symptoms, past medical history, and social history

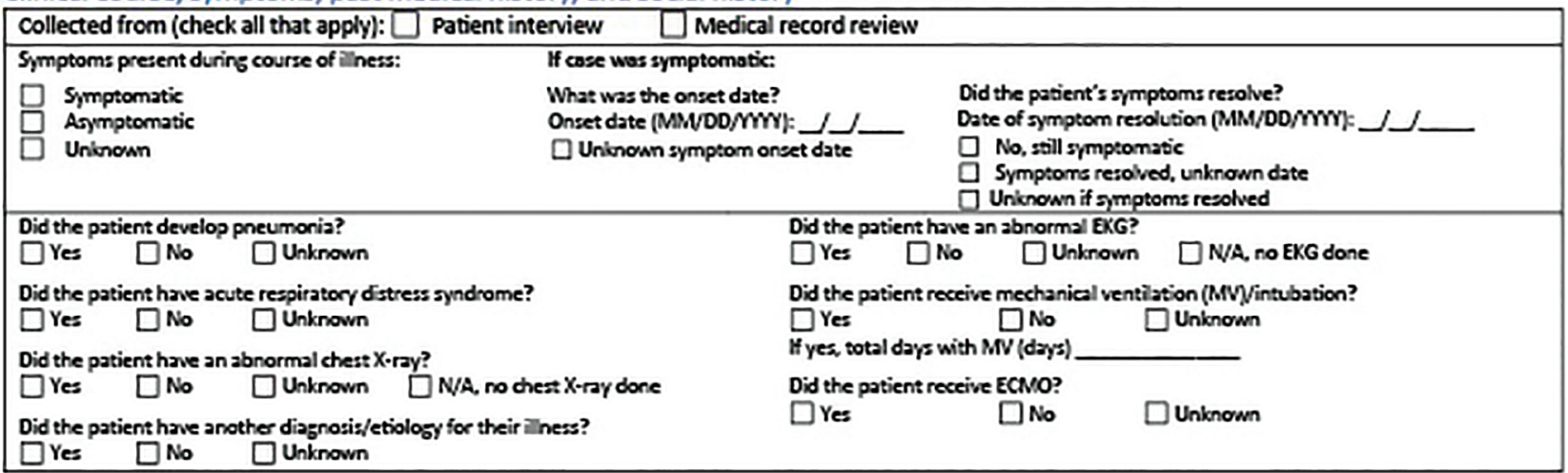

\begin{tabular}{|c|c|c|c|c|c|c|c|}
\hline \multicolumn{8}{|c|}{ If symptomatic, which of the following did the patient experience during their illness? } \\
\hline Fever $>100.4 \mathrm{~F}(38 \mathrm{C})^{\epsilon}$ & Jres & JNo & Unk & cough (new onset or worsening of chronic cough) & Yes & No & Junk \\
\hline Subjective fever (felt feverish) & Jyes & No & Junk & Wheezing & Yes & JNo & Junk \\
\hline Chills & $\square$ res & No & Unk & Shortness of breath (dyspnea) & Jes & No & Junk \\
\hline Rigors & Dres & No & Unk & Difficulty breathing & Yes & No & Junk \\
\hline Muscle aches (myalgia) & Yes & No & Unk & Chest pain & Yes & INo & Junk \\
\hline Runny nose (rhinorrhea) & Dres & No & Unk & Nausea or vomiting & Yes & No & Junk \\
\hline Sore throat & Yes & No & Unk & Abdominal pain & Yes & No & Junk \\
\hline New olfactory and taste disorder(s) & Yes & No & Unk & Diarrhea ( 23 loose stools $/ 24 \mathrm{~h}$ r period) & Yes & No & Unk \\
\hline Headache & $\square$ Yes & No & Unk & \multirow[t]{2}{*}{ Other, specify: ___ } & \multirow{2}{*}{$\square$ res } & \multirow{2}{*}{$\square$ No } & \multirow{2}{*}{$\square$ Unk } \\
\hline Fatigue & $\square$ res & $\square$ No & $\square$ Unk & & & & \\
\hline
\end{tabular}

\begin{tabular}{|c|c|c|c|c|c|c|c|}
\hline \multicolumn{8}{|c|}{ Did they have any underlying medical conditions and/or risk behaviors? $\square$ yes $\square$ No $\square$ Unknown } \\
\hline Diabetes Mellitus & Dres & INo & DUnk & Immunosuppressive condition & IYes & JNo & Junk \\
\hline Hypertension & Dres & No & Uunk & Autoimmune condition & Tres & No & Junk \\
\hline Severe obesity (BMI Z40) & $\square$ Yes & No & Unk & Current smoker & Yes & No & Junk \\
\hline Cardiovascular disease & $\square$ res & No & Junk & Former smoker & ZYes & No & Junk \\
\hline Chronic Renal disease & $\square$ Yes & No & Unk & \multirow{4}{*}{$\begin{array}{l}\text { Substance abuse or misuse } \\
\text { Disability } \\
\text { (neurologic, neurodevelopmental, intellectual, } \\
\text { physical, vision or hearing impairment) } \\
\text { If yes, specify: }\end{array}$} & Yes & No & Unk \\
\hline Chronic Liver disease & $\square$ res & $\square$ No & Uunk & & \multirow{3}{*}{$\square$ res } & \multirow{3}{*}{$\square$ No } & \multirow{3}{*}{$\square$ unk } \\
\hline $\begin{array}{l}\text { Chronic Lung disease } \\
\text { (asthma/emphysema/COPD) }\end{array}$ & $\square$ res & Wo & $\square$ Unk & & & & \\
\hline $\begin{array}{l}\text { Other chronic diseases } \\
\text { If yes, specify. }\end{array}$ & $\square$ res & $\square$ & Junk & & & & \\
\hline $\begin{array}{l}\text { Other underlying condition or risk } \\
\text { behavior, specify. }\end{array}$ & $\square$ res & $\square$ No & $\square$ Unk & $\begin{array}{l}\text { Psychological/psychiatric condition } \\
\text { If yes, specify: }\end{array}$ & $\square$ Yes & $\square$ No & $\square$ Unk \\
\hline
\end{tabular}

SARS-COV-2 Testing (approved by FDA or other designated authority)

\begin{tabular}{|l|c|c|c|c|c|}
\hline Test & POS & Neg & Indet./Inconc & Pend. & Not Done \\
\hline Molecular amplification test (RT PCR) & $\square$ & $\square$ & $\square$ & $\square$ & $\square$ \\
\hline Serologic test & $\square$ & $\square$ & $\square$ & $\square$ & $\square$ \\
\hline Other (specify): & $\square$ & $\square$ & $\square$ & $\square$ & $\square$ \\
\hline
\end{tabular}

Additional Comments or Notes

Fig. 4A: Case report form for COVID-19-infected person
Specimens for CoV-19 Testing

\begin{tabular}{|l|}
\hline Specimen ID \\
\hline 2) \\
\hline 3) \\
\hline
\end{tabular}


CDC2019-ncovid:

PATENT IDENTIFIER INFORMATION IS NOT TRANSMTTIED TOCOC.

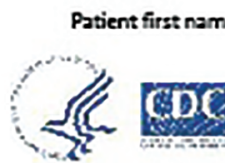

Patient last name

Date of birth (MM/DO/m)

PATENT IDENTIFIER INFORMATION IS NOT TRANSMTTED TOCDC

\section{Human Infection with 2019 Novel Coronavirus \\ Case Report Form}

\begin{tabular}{|c|c|c|c|}
\hline Reporting Jurisdiction & & Case state/local ID & \\
\hline Reporting Health Department & & CDC2019-nCOV ID & \\
\hline Contact ID & & NNDSS loc. rec. ID/Case 10s & \\
\hline 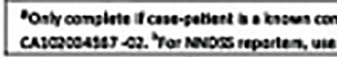 & cane-sen & 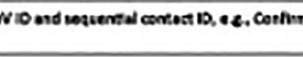 & A30502 \\
\hline Interviewer Information & & & \\
\hline Name of Interviewer: Last: & First: & Telephone: & Email: \\
\hline
\end{tabular}

Case Classification and Identification

What is the current status of this person?

$\square$ lab-confirmed case" $\square$ Probable case

If probable, select reason for case classification:

$\square$ Meets clinical criteria AND epidemiologic evidence with no confirmatory lab sesting*

$\square$ Meets presumptive lab evidence" AND esther dinical criteria OR epidemiologic evidence

$\square$ Meets vital records criteria with no confirmatory lab testing

- Detection of SARS-COV-2 RNA in a clinical specimen using a molecular amplification detection test

"Detection of speoific antigen in a dinical specimen, OR detection of specific antbody in serum plasma, or whole blood indicative of a new or resent infection

Hospitalization, ICU, and Death Information

\begin{tabular}{|l|l|l|}
\hline Was the patient hospitalized? \\
$\square$ Yes \\
If yes, admission date 1 \\
\hline Did the patient die as a result of this illness?
\end{tabular}

Case Demographics

Date of birth (MMNOD/MT)

(M)

Age: Age units (y/mo/day):

State of residence:_C County of residence:

Does this case have any tribal affiliation? $\square$ yes

Tribe name(s): _ Entolled member? $\square$ yes

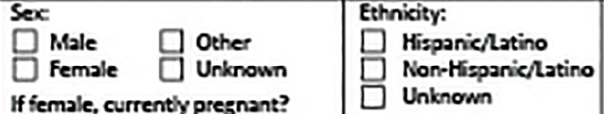

If female, currently presnant?

$\square$ Yes $\square \mathrm{No}_{0} \square$ Uniknown

Under what process was the case first identified? (chedk all that apply)
$\square$ Clinical evaluation
$\square$ Contact tracing of case pasient $\square$ Other, specity:
$\square$ EpiX notification of travelers. If yes, DGMQJD:
$\square$ Uniknown
Report date of case to COC (MM/Do/m):
Date of first positive specimen collection (MMOD/mm):

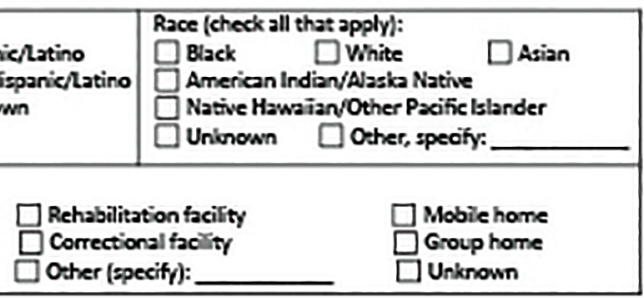

पUnknown

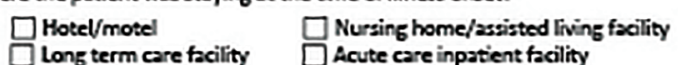

$\square$ Long term care faility

Acute care inparient facility

$\square$ Outside, in a car, or ocher location nos meant for human habitation

Healthcare Worker Information

Is the patient a healthcare worker in the United States? $\square$ Yes $\square$ No $\square$ Uniknown

If yes, what is their oceupation (type of job)?

$\square$ Nurse $\square$ Emironmental senvices $\square$ Uniknown

\author{
$\square$ Hospital
}

$\square$ Rehabilitation faility $\square$ Other, specify: $\square$ Nursing home/assisted living faclity $\square$ Unknown

\section{Exposure Information}

In the 14 days prior to illness onset did the patient have any of the following exposures (check all that apply):

$\square$ Domestic travel (outzide state of normal residence). Specify state(s):

International travel. Specify country's):

Crise ship or vessel travel as passenger or crew member. Specify name of ship:

$\square$ Workplace

If yes, is the workplace critical infrastructure (e.5., healthcare setting. grocery store)?

$\square$ Yes, specify workplace setting:

$\square$ No $\square$ Unknown

$\square$ Contact with a known COVD-19 case (probable or confirmed)

If the patient had contact with a known COND-19 case:

What type of contact?

$\square$ Household contact

$\square$ Commurity-associated contact

$\square$ Airport/airplane

$\square$ Healthcare-associated contact (patient, visitor, or healthcare worker)

Fig. 4B: Case report form for COVID-19-infected person

\section{Donning and doffing (Figs 5A to 5C)}

Technical Approaches and Equipment to Help Reduce Transmission (Handpieces, Equipment, etc.)

- Since SARS-CoV-2 may be vulnerable to oxidation, use $1.5 \%$ hydrogen peroxide (commercially available in India) or $0.2 \%$ povidone as a pre-procedural mouth rinse. There are no clinical studies supporting the virucidal effects of any pre-procedural mouth rinse against SARS-CoV-2.

- Dental healthcare personnel may use "extraoral dental radiographs, such as panoramic radiographs or cone beam CT, are appropriate alternatives" to intraoral dental radiographs 


\section{SEQUENCE FOR PUTTING ON}

\section{PERSONAL PROTECTIVE EQUIPMENT (PPE)}

The type of PPE used will vary based on the level of precautions required, such as standard and contact, droplet or airbome infection isolation precautions. The procedure for putting on and removing PPE should be tailored to the specific type of PPE.

\section{GOWN}

- Fully cover torso from neck to knees, arms to end of wrists, and wrap around the back

- Fasten in back of neck and waist
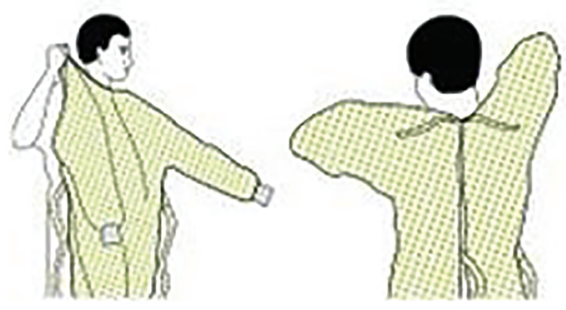

\section{MASK OR RESPIRATOR}

- Secure ties or elastic bands at middle of head and neck

- Fit flexible band to nose bridge

- Fit snug to face and below chin

- Fit-check respirator
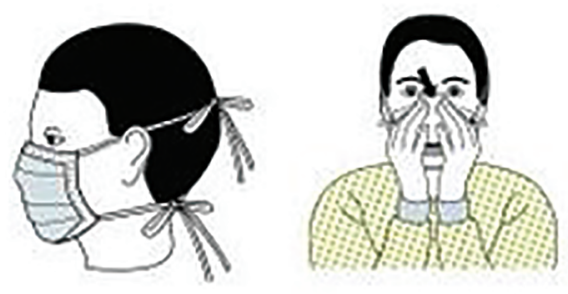

\section{GOGGLES OR FACE SHIELD}

- Place over face and eyes and adjust to fit
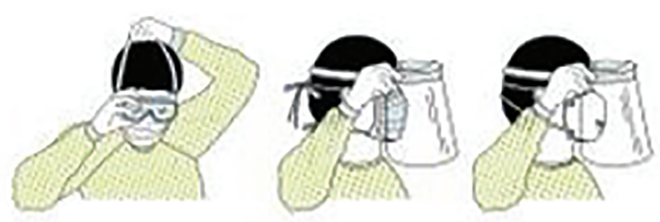

\section{GLOVES}

- Extend to cover wrist of isolation gown

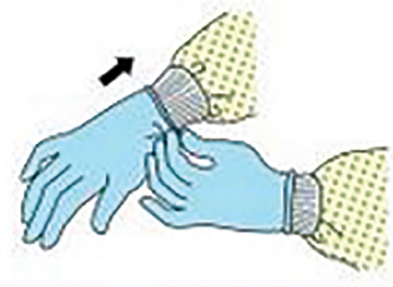

\section{USE SAFE WORK PRACTICES TO PROTECT YOURSELF} AND LIMIT THE SPREAD OF CONTAMINATION

- Keep hands away from face

- Limit surfaces touched

- Change gloves when torn or heavily contaminated

A

- Perform hand hygiene

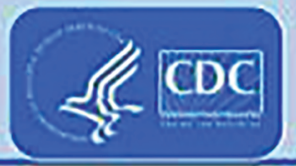

Fig. 5A: Donning during dental care 
HOWTO SAFELY REMOVE PERSONAL PROTECTIVE EQUIPMENT (PPE) EXAMPLE 1

There are a variety of ways to safely remove PPE without contaminating your clothing, skin, or mucous membranes with potentially infectious materials. Here is one example. Remove all PPE before exiting the patient room except a respirator, if worn. Remove the respirator after leaving the patient room and closing the door. Remove PPE in the following sequence:

\section{GLOVES}

- Outside of gloves are contaminated!

- If your hands get contaminated during glove removal, immediately wash your hands or use an alcohol-based hand sanitizer

- Using a gloved hand, grasp the palm area of the other gloved hand and peel off first glove

- Hold removed glove in gloved hand

- Slide fingers of ungloved hand under remaining glove at wrist and peel off second glove over first glove

- Discard gloves in an infectious* waste container
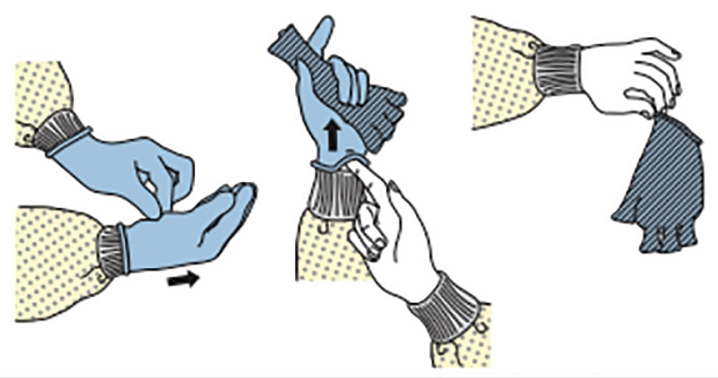

\section{GOGGLES OR FACE SHIELD}

- Outside of goggles or face shield are contaminated!

- If your hands get contaminated during goggles or face shield removal, immediately wash your hands or use an alcohol-based hand sanitizer

- Remove goggles or face shield from the back by lifting head band or ear pieces

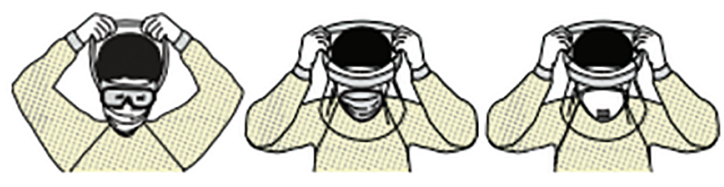

- If the item is reusable, place in designated receptacle for reprocessing. Otherwise, discard in an infectious* ${ }^{*}$ waste container

\section{GOWN}

- Gown front and sleeves are contaminated!

- If your hands get contaminated during gown removal, immediately wash your hands or use an alcohol-based hand sanitizer

- Unfasten gown ties, taking care that sleeves don't contact your body when reaching for ties

- Pull gown away from neck and shoulders, touching inside of gown only

- Turn gown inside out

- Fold or roll into a bundle and discard in an infectious* waste container

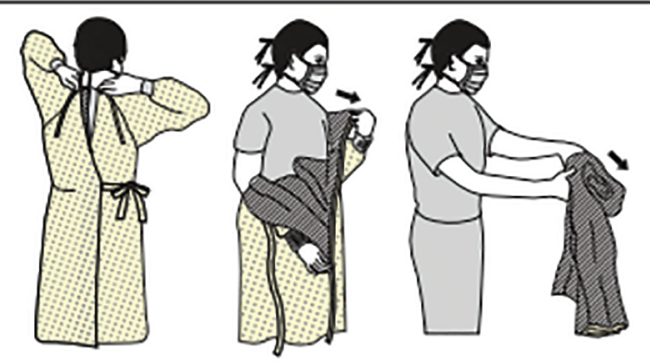

\section{MASK OR RESPIRATOR}

- Front of mask/respirator is contaminated - DO NOT TOUCH!

- If your hands get contaminated during mask/respirator removal, immediately wash your hands or use an alcohol-based hand sanitizer

- Grasp bottom ties or elastics of the mask/respirator, then the ones at the top, and remove without touching the front
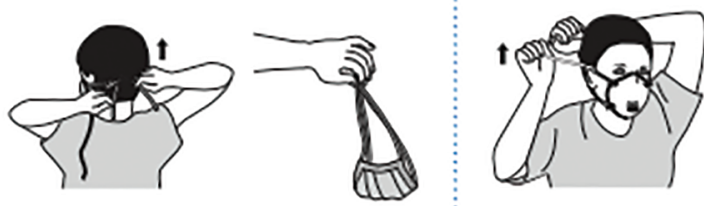

- Discard in an infectious* waste container

\section{WASH HANDS OR USE AN}

\section{ALCOHOL-BASED HAND SANITIZER IMMEDIATELY AFTER REMOVING \\ ALL PPE}

${ }^{*}$ An infectious waste container is used to dispose of PPE that is potentially contaminated with Ebola virus.
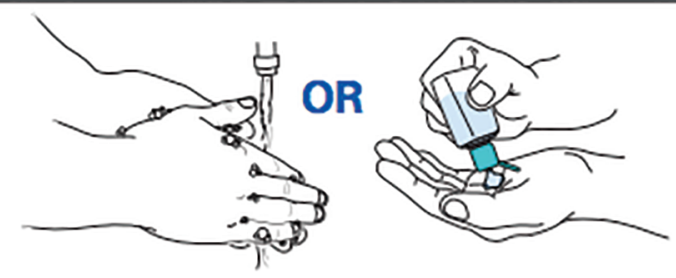

\section{PERFORM HAND HYGIENE BETWEEN STEPS IF HANDS BECOME CONTAMINATED AND IMMEDIATELY AFTER REMOVING ALL PPE \\ B}

Fig. 5B: Doffing during dental care (example 1) 


\section{HOW TO SAFELY REMOVE PERSONAL PROTECTIVE EQUIPMENT (PPE) EXAMPLE 2}

Here is another way to safely remove PPE without contaminating your clothing, skin, or mucous membranes with potentially infectious materials. Remove all PPE before exiting the patient room except a respirator, if worn. Remove the respirator after leaving the patient room and closing the door. Remove PPE in the following sequence:

\section{GOWN AND GLOVES}

- Gown front and sleeves and the outside of gloves are contaminated!

- If your hands get contaminated during gown or glove removal, immediately wash your hands or use an alcohol-based hand sanitizer

- Grasp the gown in the front and pull away from your body so that the ties break, touching outside of gown only with gloved hands

- While removing the gown, fold or roll the gown inside-out into a bundle

- As you are removing the gown, peel off your gloves at the same time, only touching the inside of the gloves and gown with your bare hands. Place the gown and gloves into a waste container
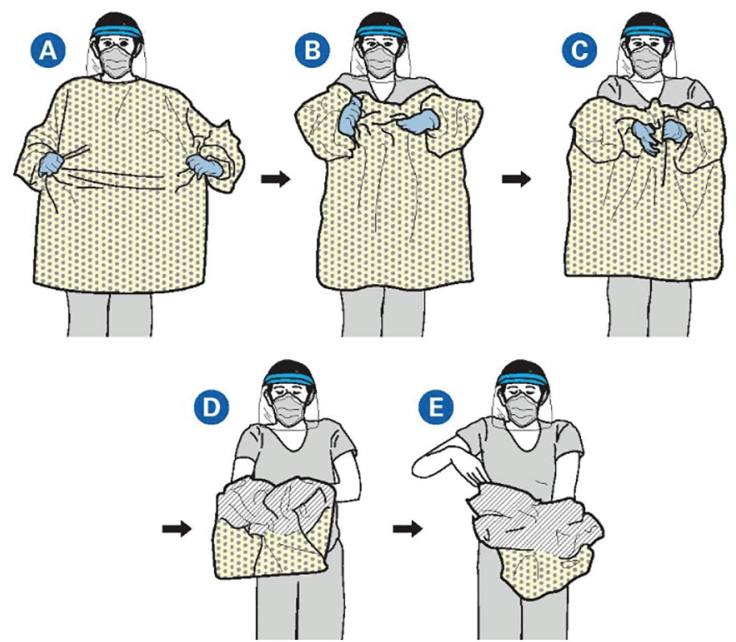

\section{GOGGLES OR FACE SHIELD}

- Outside of goggles or face shield are contaminated!

- If your hands get contaminated during goggles or face shield removal, immediately wash your hands or use an alcohol-based hand sanitizer

- Remove goggles or face shield from the back by lifting head band and without touching the front of the goggles or face shield

- If the item is reusable, place in designated receptacle for reprocessing. Otherwise, discard in a waste container

\section{MASK OR RESPIRATOR}

- Front of mask/respirator is contaminated - DO NOT TOUCH!

- If your hands get contaminated during mask/respirator removal, immediately wash your hands or use an alcohol-based hand sanitizer

- Grasp bottom ties or elastics of the mask/respirator, then the ones at the top, and remove without touching the front

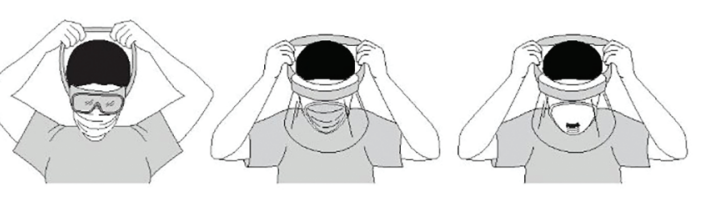

- Discard in a waste container

\section{WASH HANDS OR USE AN} ALCOHOL-BASED HAND SANITIZER IMMEDIATELY AFTER REMOVING ALL PPE
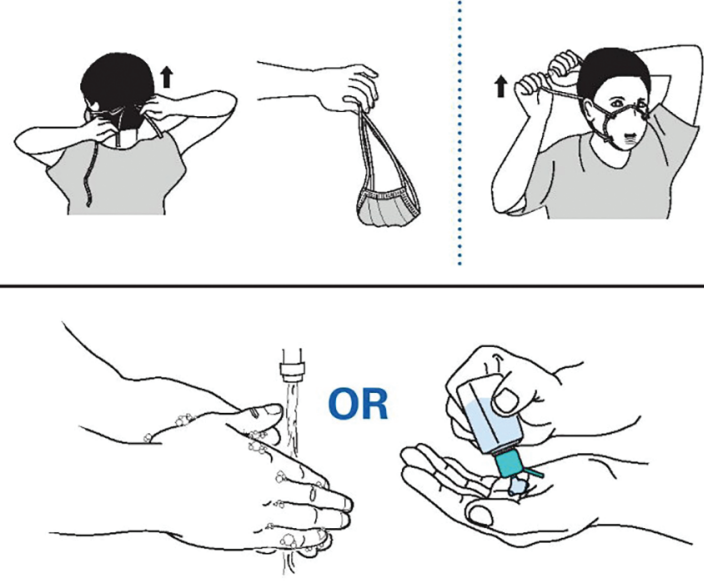

\section{PERFORM HAND HYGIENE BETWEEN STEPS IF HANDS BECOME CONTAMINATED AND IMMEDIATELY AFTER REMOVING ALL PPE c (1)}

Fig. 5C: Doffing during dental care (example 2) 
during the outbreak of COVID-19, as the latter can stimulate saliva secretion and coughing.

- Reduce aerosol production as much as possible, as the transmission of COVID-19 seems to occur via droplets or aerosols, and DHCP should prioritize the use of hand instrumentation. Carisolv and hand scaler are recommended for caries removal and periodontal scaling, in order to minimize the generation of aerosol as much as possible.

- Dental healthcare personnel should use rubber dams if an aerosol-producing procedure is being performed to help minimize aerosol or spatter.

- Dental healthcare personnel may use a four-handed technique for controlling infection.

- Anti-retraction functions of handpieces may provide additional protection against cross-contamination.

- Dental healthcare personnel should prefer the use of highvolume evacuators. Dental healthcare personnel "should be aware that in certain situations, backflow could occur when using a saliva ejector," and "this backflow can be a potential source of cross contamination".

- Dental healthcare personnel should use reabsorbable sutures (i.e., sutures that last 3-5 days in the oral cavity) to eliminate the need for a follow-up appointment.

- Dental healthcare personnel should minimize the use of a 3-in-1 syringe as this may create droplets due to forcible ejection of water/air.

- Disinfectants (hypochlorite, ethanol) in the handpiece and 3-in-1 syringe water supplies have been reported to reduce viral contaminants in splatter, but its action on human coronavirus is unknown.

\section{Steps after Suspected, Unintentional Exposure}

Follow CDC recommendations in the event of suspected unintentional exposure (e.g., unprotected direct contact with secretions or excretions from the patient).

- Aerosol-generating procedures should be scheduled as the last appointment of the day. For an aerosol-generating procedure performed without N-95 masks and only using surgical facemasks, regardless of disinfection procedures being effectively executed, subsequent patients, and DHCP are at moderate risk for COVID-19 infection and transmission. Given that asymptomatic patients may carry the virus, CDC suggests a 14-day quarantine. Alternatively, take all precautions to prevent transmission and require that the patient is tested for COVID-19 immediately after dental treatment; if positive, DHCP should quarantine for 14 days.

- Patients referred for COVID-19 testing should be given detailed instructions on when/where to go for testing, how to justify the need for testing to the testing facility visited, and how to contact the dental clinic to report test results (Algorithm 3). If a test is positive, the clinic needs to report the exposure to all patients treated after the infected patient.

\section{After Dental Care is Provided}

\section{In-between Patients}

- Clean (PPE) with soap and water, or if visibly soiled, clean and disinfect reusable facial protective equipment (e.g., clinician and patient protective eyewear or face shields) between patients.
- Non-dedicated and non-disposable equipment (e.g., handpieces, dental X-ray equipment, dental chair, and light) should be disinfected according to the manufacturer's instructions. Handpieces should be cleaned to remove debris, followed by heat sterilization after each patient.

- Routine cleaning and disinfection procedures (e.g., using cleaners and water to preclean surfaces prior to applying an environmental protection agency (EPA)-registered, hospitalgrade disinfectant to frequently touched surfaces or objects for appropriate contact times as indicated on the product's label) are appropriate for SARS-CoV-2 in healthcare settings, including those patient-care areas in which aerosol-generating procedures are performed.

- Surfaces, such as door handles, chairs, desks, elevators, and bathrooms, should be cleaned and disinfected frequently.

\section{Postoperative Instructions for Patients}

- In light of the controversy regarding whether ibuprofen should be used for patients with a COVID-19 infection, it is recommended to use ibuprofen as normally indicated while managing any type of pain. For example, for the management of pulpal- and periapical-related dental pain and intraoral swelling in immunocompetent adults, it is recommended that nonsteroidal anti-inflammatory drugs (NSAIDs) in combination with acetaminophen (i.e., 400-600 mg ibuprofen plus 1,000 mg acetaminophen) can still be used.

- While treating patients with dental pain and intraoral swelling, dentists should determine whether definitive, conservative dental treatment (i.e., pulpotomy, pulpectomy, non-surgical root canal treatment, or incision for drainage of abscess) is available. The 2019 ADA clinical practice recommendations regarding the use of antibiotics are still applicable for immunocompetent adult patients with symptomatic irreversible pulpitis with or without symptomatic apical periodontitis, pulp necrosis and symptomatic apical periodontitis, or pulp necrosis and localized acute abscess, and should be referred to a dental specialist while determining the recommended course of action.

\section{When Going Home after a Workday}

Dental healthcare personnel should change from scrubs to personal clothing before returning home. Upon arriving home, DHCPs should take off shoes, remove and wash clothing (separately from other household residents), and immediately shower.

\section{Conclusion}

The novel coronavirus (2019-nCoV) is rapidly increasing in terms of cases and evidence of human-to-human transmission suggested that the virus was more contagious than SARS-CoV and MERSCoV9. ${ }^{25,27,29}$ Although dental clinics have been closed due the epidemic, a large number of emergency patients still go to the dental clinics for treatment. We have summarized the possible transmission routes of 2019-nCoV. We also reviewed several detailed practical strategies to block virus transmission to provide a reference for preventing the transmission of 2019-nCoV during dental diagnosis and treatment. Healthcare providers must keep 
themselves updated about this evolving disease and provide adequate training to their staff.

\section{References}

1. Wang $C$, Horby PW, Hayden FG, et al. A novel coronavirus outbreak of global health concern. Lancet 2020;395(10223):470-473. DOI: 10.1016/ S0140-6736(20)30185-9.

2. Coronavirus Outbreak. Available at: https://www.worldometers.info/ coronavirus/. Accessed 15th April 2020.

3. Coronavirus - an overview $\mid$ ScienceDirect Topics. www.sciencedirect. com. Retrieved 2020-04-02.

4. Wax RS, Christian MD. Practical recommendations for critical care and anaesthesiology teams caring for novel coronavirus (2019nCoV) patients. Can J Anaesth 2020;67(5):568-576. DOI: https://doi. org/10.1007/s12630-020-01591-x.Accessed 18 March, 2020.

5. Zhou $P$, Yang $X-L$, Wang $X-G$, et al. A pneumonia outbreak associated with a new coronavirus of probable bat origin. Nature 2020;579(7798):270-273. DOI: 10.1038/s41586-020-2012-7.

6. Wahba $L$, Jain $N$, Fire $A Z$, et al. Identification of a pangolin niche for a 2019-nCoV-like coronavirus through an extensive metametagenomic search. bioRxiv 2020. DOI: 10.1101/2020.02.08.939660.

7. Wuhan Municipal Health Commission. Press statement related to novel coronavirus infection (in Chinese) http://wjw.wuhan.gov.cn/ front/web/showDetail/2020012709194 (2020).

8. Situation Report-67 SITUATION IN NUMBERS total and new cases in last 24 hours. Available at: https://who.int/docs/default-source/ coronaviruse/situation-reports/20200327-sitrep-67-covid-19. pdf?sfvrsn5b65f68eb_4 Accessed 20 April, 2020.

9. Lan $L, X u D, Y e G$, et al. Positive RT-PCR test results in patients recovered from COVID-19. JAMA 2020;323(15):1502-1503. DOI: 10.1001/jama.2020.2783.

10. Lu C-W, Liu X-F, Jia Z-F. 2019-nCoV transmission through the ocular surface must not be ignored. The Lancet 2020;395(10224):e39. DOI: 10.1016/S0140-6736(20)30313-5.

11. Huang C, Wang Y, Li X, et al. Clinical features of patients infected with 2019 novel coronavirus in Wuhan, China. Lancet 2020;395(10223): 497-506. DOI: 10.1016/S0140-6736(20)30183-5.

12. To KKW, Tsang OTY, Yip CCY, et al. Consistent detection of 2019 novel coronavirus in saliva. Clin Infect Diseases 2020(15). DOI: 10.1093/cid/ ciaa149.

13. Belser JA, Rota PA, Tumpey TM. Ocular tropism of respiratory viruses. Microbiol Mol Biol Rev 2013;77(1):144-156. DOI: 10.1128/MMBR. 00058-12.

14. World Health Organization. Situation reports. Available at: https:// www.who.int/emergencies/diseases/novel-coronavirus-2019/ situation-reports/ Accessed 14 April 2020.

15. Chen $\mathrm{H}$, Guo J, Wang C, et al. Clinical characteristics and intrauterine vertical transmission potential of COVID-19 infection in nine pregnant women: a retrospective review ofmedical records. Lancet 2020;95(10226):809-815. DOI: 10.1016/S0140-6736(20)30360-3.

16. Rodriguez-Morales AJ, MacGregor K, Kanagarajah S, et al. Going global - travel and the 2019 novel coronavirus. Travel Med Infect Dis 2020;33:101578. DOI: 10.1016/j.tmaid.2020.101578.

17. Kampf G, Todt D, Pfaender S, et al. Persistence of coronaviruses on inanimate surfaces and its inactivation with biocidal agents. J Hosp Infect 2020;104(3):246-251. DOI: 10.1016/j.jhin.2020.01.022.

18. Chen J. Pathogenicity and transmissibility of 2019-nCoV—a quick overview and comparison with other emerging viruses. Microb Infect 2020;22(2):69-71. DOI: 10.1016/j.micinf.2020.01.004.
19. Cleveland JL, Gray SK, Harte JA, et al. Transmission of blood-borne pathogens in US dental health care settings: 2016 update. J Am Dent Assoc (1939) 2016;147(9):729-738. DOI: 10.1016/j.adaj.2016. 03.020.

20. Harrel SK, Molinari J. Aerosols and splatter in dentistry: a brief review of the literature and infection control implications. J Am Dent Assoc (1939) 2004;135(4):429-437. DOI: 10.14219/jada.archive.2004. 0207.

21. Liu L, Wei Q, Alvarez X, et al. Epithelial cells lining salivary gland ducts are early target cells of severe acute respiratory syndrome coronavirus infection in the upper respiratory tracts of rhesus macaques. J Virol 2011;85(8):4025-4030. DOI: 10.1128/JVI.02292-10.

22. Peng X, Xu X, Li Y, et al. Transmission routes of 2019-nCoV and controls in dental practice. Int JOral Sci 2020;12(1):9. DOI: 10.1038/s41368-0200075-9.

23. Jin $\mathrm{YH}$, Cai $\mathrm{L}, \mathrm{Cheng} \mathrm{ZS}$, et al. A rapid advice guideline for the diagnosis and treatment of 2019 novel coronavirus [2019-nCoV] infected pneumonia [standard version]. Mil Med Res 2020;7(1):4. DOI: 10.1186/ s40779-020-0233-6.

24. Huang P, Liu T, Huang L, et al. Use of chest CTin combination with negative RT-PCR assay for the 2019 novel coronavirus but high clinical suspicion. Radiology 2020;295(1):22-23. DOI: https://doi.org/10.1148/ radiol.2020200330.

25. Backer JA, Klinkenberg D, Wallinga J. Incubation period of 2019 novel coronavirus (2019-nCoV) infections among travellers from Wuhan, china. Euro Surveill 2020;25(5):2000062. DOI: 10.2807/1560-7917. ES.2020.2825.2805.2000062.

26. Zhang J, Wang S, Xue Y. Fecal specimen diagnosis 2019 novel coronavirus-infected pneumonia. J Med Virol 2020. DOI: 10.1002/ jmv.25742.

27. Hoffmann $M$, Kleine-Weber $\mathrm{H}$, Schroeder $\mathrm{S}$, et al. SARS-CoV-2 cell entry depends on ACE2 and TMPRSS2 and is blocked by a clinically proven protease inhibitor. Cell 2020;181(2):271-280.e8. DOI: 1016/j. cell.2020.02.052.

28. Sabino-Silva R, Jardim ACG, Siqueira WL. Coronavirus COVID19 impacts to dentistry and potential salivary diagnosis. Clin Oral Investig 2020;24(4):1619-1621. DOI: 10.1007/s00784-02003248-x.

29. Kohn WG, Collins AS, Cleveland JL, et al., Centers for Disease Control and Prevention. 2003. Guidelines for infection control in dental health-care settings-2003. https://www.cdc.gov/mmwr/preview/ mmwrhtml/rr5217a1.htm.

30. Meng L, Hua F, Bian Z. Coronavirus disease 2019 (COVID-19): emerging and future challenges for dental and oral medicine. J Dent Res 2020;99(5):481-487. DOI: 10.1177/0022034520914246.

31. Chang $D, X u H$, Rebaza $A$, et al. Protecting health-care workers from subclinical coronavirus infection. Lancet Respir Med 2020;8(3):e13. DOI: 10.1016/S2213-2600(20)30066-7.

32. Gamio L, The Workers Who Face the Greatest Coronavirus Risk. Available online: https://www.nytimes.com/interactive/2020/03/15/ business/economy/coronavirus-worker-risk.html?action=click\&mod ule $=$ Top+Stories\&pgtype $=$ Homepage Accessed on 15 March 2020.

33. ADA Interim Guidance for Minimizing Risk of COVID-19 Transmission. Available from https://www.ada.org/ /media/CPS/Files/COVID/ ADA_COVID_Int_Guidance_Treat_Pts.pdf Accessed on 18th April 2020.

34. ADA Interim Guidance for Management of Emergency and Urgent Dental Care. Available from https://www.ada.org/ /media/CPS/Files/ COVID/ADA_Int_Guidance_Mgmt_Emerg-Urg_Dental_COVID19.pdf Accessed on 19th April 2020. 